\title{
Cryptococcosis in Colombian children and literature review
}

\author{
Jairo Lizarazo', Patricia Escandón²/+, Clara Inés Agudelo², Elizabeth Castañeda² \\ ${ }^{1}$ Hospital Universitario Erasmo Meoz, Cúcuta, Colombia ${ }^{2}$ Instituto Nacional de Salud, Bogotá, Colombia
}

Cryptococcosis is reported in adults and is often acquired immune deficiency syndrome (AIDS)-associated; however, its frequency in children is low. Based on the National Survey on Cryptococcosis conducted in Colombia, an epidemiological and clinical analysis was performed on cases of the disease observed in children less than 16 years old between 1993-2010. We found 41 affected children (2.6\% prevalence) from the 1,578 surveys received. The country mean annual incidence rate was 0.017 cases 1100,000 children under 16 years, while in Norte de Santander the incidence rate was 0.122 cases $/ 100,000(p<0.0001)$. The average age of infected children was 8.4 and $58.5 \%$ were male. In $46.3 \%$ of cases, a risk factor was not identified, while $24.4 \%$ had AIDS. The most frequent clinical manifestations were headache (78.1\%), fever (68.8\%), nausea and vomiting (65.6\%), confusion (50\%) and meningeal signs (37.5\%). Meningitis was the most frequent clinical presentation (87.8\%). Amphotericin B was given to $93.5 \%$ of patients as an initial treatment. Positive microbiological identification was accomplished by India ink (94.7\%), latex in cerebrospinal fluid (100\%) and culture (89.5\%). Out of 34 isolates studied, Cryptococcus neoformans var. grubii (VNI 85.3\%, VNII 8.8\%) was isolated in $94.1 \%$ of cases and Cryptococcus gattii (VGII) was isolated in $5.9 \%$ of cases. These data are complemented by a literature review, which overall suggests that cryptococcosis in children is an unusual event worldwide.

Key words: Cryptococcus neoformans - Cryptococcus gattii - cryptococcosis - cryptococcal meningitis - epidemiology - Colombia

Cryptococcosis is a systemic fungal infection that often affects adults, especially those who have an alteration in their cellular immunity. Within a year, approximately one million cases of meningeal cryptococcosis in people with acquired immune deficiency syndrome (AIDS) are diagnosed and of these people, almost twothirds die (Park et al. 2009).

In contrast, worldwide literature has described less than one thousand cases of cryptococcosis in children (Meiring et al. 2012), including those occurring in immunosuppressed patients. The low frequency of cryptococcosis in children cannot be explained by lack of exposure; in fact, one study shows that the majority of children older than two years have serological evidence of infection by Cryptococcus neoformans (Goldman et al. 2001).

In Colombia, a National Survey on Cryptococcosis that has been conducted since 1993 has allowed us to estimate a more realistic picture of this mycosis (Lizarazo et al. 2007, Escandón et al. 2012). The mean annual incidence of cryptococcosis in the general population in Colombia was 2.4 cases per $10^{6}$ people between $1995-2010$; in the population with human immunodeficiency virus (HIV), the incidence ranged between 3-3.3 cases per $10^{3}$ people (Lizarazo et al. 2007, Escandón et al. 2012). With the data obtained from the National Survey, we aimed to analyse the epidemiology and clinical manifestations of cryptococcosis in Colombian children.

doi: $10.1590 / 0074-0276130537$

+ Corresponding author: pescandon@ins.gov.co

Received 14 November 2013

Accepted 14 July 2014

\section{PATIENTS, MATERIALS AND METHODS}

Study design - This is an observational descriptive study where epidemiological and clinical data from cases of cryptococcosis in children during the years of 1993-2010 were extracted from the National Survey mentioned above.

The National survey was designed in accordance with the guidelines given by the European Confederation of Medical Mycology, with the corresponding authorisation (Viviani 1997), and processed by clinicians and microbiologists of public, academic and private hospitals, as well as public health laboratories of Colombia.

The survey recorded patient data such as demographic data, sex, year of birth and department (Colombian political divisions), department of residence, risk factors (AIDS, corticosteroid therapy, autoimmune disease, transplantation, solid tumour, haematologic malignancy, diabetes mellitus, kidney failure and cirrhosis), date of clinical diagnosis, signs and symptoms (fever, headache, nausea or vomiting, confusion, mental changes, cough, abnormal vision or loss of vision, focal neurological signs, meningeal signs, hydrocephalus, intracranial hypertension without hydrocephalus, seizures), chest radiographic findings, computerised tomography (CT) and magnetic resonance imaging (MRI). The laboratory results of the tests included the origin of the positive sample for the fungus, results of the direct examination, culture and antigenaemia. Additionally, information was requested for the initial treatment given for cryptococcosis.

The surveys and isolates of the fungus were sent to the two focal points of the study: the National Institutes of Health (INS), in Bogotá, and the Corporation for Biological Research (CIB) of Medellin. With these data, we created a database using the program Epi Info 6.0 that was used for analysis (Dean et al. 1994). Children were considered as individual minors of 16 years. 
Ethical considerations - This study was approved by the Ethical Committee of the CIB. Additionally, this study was endorsed by the technical and ethical committees of the INS.

Case definition - A case of cryptococcosis was defined in subjects who presented clinical findings compatible with cryptococcosis in addition to the presence of one or more of the following laboratory results: visualisation of the fungus under direct examination with India ink of cerebrospinal fluid (CSF) from a skin lesion or from a histopathological examination, isolation of $C$. neoformans or Cryptococcus gattii from a normally sterile site, bronchoalveolar lavage or skin lesion and a titre $\geq 8$ capsular antigen in serum or any titre in the CSF.

An AIDS case was considered in those where HIV infection was reported in the survey and AIDS was not considered in those who were negative for HIV infection or in those for whom this information had not been registered.

Epidemiological analysis - Prevalence - The proportion of the number of cases in children was established from the total number of surveys received. This was established at both the national and regional levels.

Incidence - The average annual incidence was determined by using as a denominator the average of the population of both Colombia and the departments from 1993-2010, as determined by the National Administrative Department of Statistics (DANE 2013). However, an important consideration is that this is a passive and voluntary survey.

Statistical analysis - The national incidence rate was determined for each department as well as nationally. Subsequently, these rates were compared using a ratio with the respective confidence interval of $95 \%$ using the Poisson distribution and the $p$ value was calculated according to a value of 0.05 considered as statistically significant to determine differences in the incidence of disease.

Microbiology - The identification of disease was made using conventional methods and species determination was performed using culture in CGB medium (Kwon-Chung et al. 1982). In the first years, the serotype (B or C) was determined using specific antisera commercially available at that time (Crypto-Check, Iatron Laboratories, Japan).

Molecular type and mating type - The molecular type was determined in all isolates using polymerase chain reaction fingerprinting with the $(\mathrm{GTG})_{5}$ primer (Meyer et al. 2003). Mating type a or alpha was determined using specific primers described previously (Halliday \& Carter 2003).

Review of the literature - A search was performed in the MEDLINE database from 1996 through 30 September 2013 using the following search terms in English: cryptococcosis, C. neoformans and Cryptococcus gattii, HIV, AIDS, children and epidemiology. In addition, we searched for articles in Spanish and Portuguese in the databases SciELO and LILACS. We took into account the articles that included epidemiological data. We removed the case reports or articles whose full text was not achieved. We added several references cited in articles obtained in the primary search.

\section{RESULTS}

Prevalence, incidence of cases and origin - A total of 1,578 surveys were received from 76 centres and 25 departments and Bogotá DC over a period of 18 years (1993-2010). Forty-one surveys (2.6\%) were from children under 16 years.

Children completing surveys were from the following departments: Cundinamarca/Bogotá DC [10 (24.3\%)], Norte de Santander [9 (22\%)], Valle [5 (12.2\%)], Antioquia [4 (9.8\%)], Huila [3 (7.3\%)], Tolima [3 (7.3\%)], Santander [2 (4.9\%)], Caquetá [2 (4.9\%)], Bolívar [1 (2.4\%)], Nariño [1 (2.4\%)] and Risaralda [1 (2.4\%)] (Fig. 1).

The mean annual incidence of cryptococcosis in children in Colombia was 0.017 cases per 100,000 children under 16 years; however, in one of the northeastern departments, Norte de Santander, this incidence reached 0.122 cases per $100,000(\mathrm{p}<0.0001)$.

Demographic information - The average age of the patients was $8.4 \pm 4.7$ years and $21(58.5 \%)$ patients were male. The distribution according to age and sex is contained in Fig. 2.

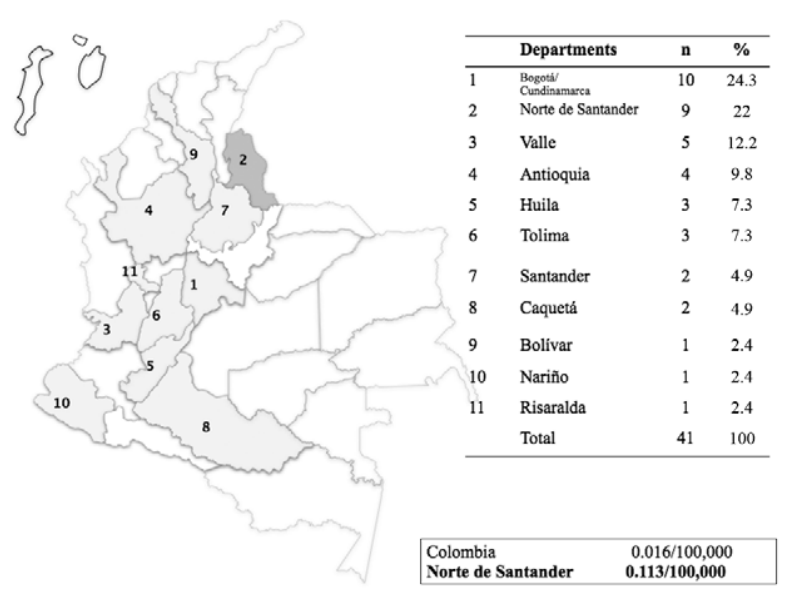

Fig. 1: mean annual incidence of cryptococcosis in children $<16$ years.

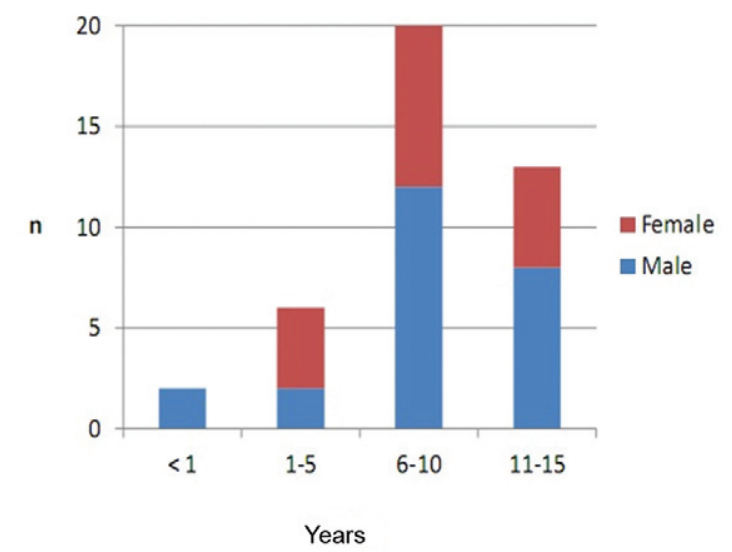

Fig. 2: cryptococcosis in Colombian children 1993-2010. 
Risk factors - No risk factor was identified in 19 cases $(46.3 \%)$. The risk factors were HIV infection in 10 patients $(24.4 \%)$, autoimmune disease, corticosteroid use, haematologic malnutrition and malignancy in three cases each (7.3\%) and renal disease, solid tumour and prematurity with one case each $(2.3 \%)$.

Clinical findings - The most frequent clinical manifestations were headache (78.1\%), fever $(68.8 \%)$, nausea and vomiting (65.6\%), confusion $(50 \%)$ and meningeal signs $(37.5 \%)$. The totals of the clinical manifestations informed are reflected in Table I.

The most common clinical form of presentation of the disease was neurocryptococcosis $(87.8 \%)$ followed by the disseminated form (12.2\%). Among the five patients with disseminated disease, two had skin involvement.

Diagnostic images - In five patients, one of them $\mathrm{HIV}+$, results of a chest X-ray were reported and this diagnostic was abnormal in four of them. The abnormality described for each of these was the presence of pulmonary infiltrates. A skull tomography was performed in 14 patients, four of them $\mathrm{HIV}+$, and abnormalities were reported in 10 . The abnormalities described were brain hypodensities ( 3 cases), increase of the meningeal enhancement ( 3 cases), hydrocephalus ( 2 cases), calcifications (1 case), brain mass (1 case) and cerebral haemorrhage (1 case). Some patients had more than one abnormality.

Treatment - In total, $75.6 \%$ of the patients were treated with antifungal agents, two patients did not receive treatment and this information was not available for eight patients. The medication most often used was amphotericin B (AmB) (93.5\%). The different therapeutic regimens are listed in Table II.

Laboratory diagnosis - Several diagnostic methods were performed: direct examination, determination of the capsular antigen in serum and CSF and CSF and respiratory samples culture. The results of these tests are described in Table III.

Serotypes and molecular types - From a total of 34 isolates studied, 94.1\%, were serotype A (molecular pat-

TABLE I

Clinical manifestations of cryptococcosis in children

\begin{tabular}{lc}
\hline Clinical findings & $\mathrm{n}(\%)$ \\
\hline Headache & $25(78.1)$ \\
Fever & $22(68.8)$ \\
Nausea and vomiting & $21(65.6)$ \\
Confusion & $16(50)$ \\
Meningeal signs & $12(37.5)$ \\
Visual alterations & $9(28.1)$ \\
Seizures & $9(28.1)$ \\
Cough & $6(18.8)$ \\
Neurological signs & $6(18.8)$ \\
Hydrocephalus & $6(18.8)$ \\
Loss weight & $2(6.2)$ \\
\hline
\end{tabular}

$\mathrm{n}=32$.
TABLE II

Pharmacological treatment of cryptococcosis in Colombian children

\begin{tabular}{lc}
\hline Treatment & n/total (\%) \\
\hline Patients with treatment & $31 / 41(75.6)$ \\
Type of antifungal used & \\
AmB & $29 / 31(93.5)$ \\
5 FC & $4 / 31(12.9)$ \\
FCZ & $8 / 31(25.8)$ \\
ITZ & $1 / 31(3.2)$ \\
Caspofungin & $1 / 31(3.2)$ \\
Therapeutic regimens used & \\
AmB only & $19 / 31(61.3)$ \\
AmB + FCZ & $5 / 31(16.1)$ \\
AmB + 5FC & $2 / 31(6.4)$ \\
AmB + 5FC + FCZ & $1 / 31(3.2)$ \\
AmB + ITZ & $1 / 31(3.2)$ \\
AmB + caspofungin & $1 / 31(3.2)$ \\
5 FC + FCZ & $1 / 31(3.2)$ \\
FCZ only & $1 / 31(3.2)$ \\
Patients without treatment & $2 / 41(4.9)$ \\
Patients without treatment information & $8 / 41(19.5)$ \\
\hline AmB: amphotericin B; FCZ: fluco
\end{tabular}

AmB: amphotericin B; FCZ: fluconazole; ITZ: itraconazole; 5FC: 5-fluorocytosin.

TABLE III

Results of the laboratory examinations

\begin{tabular}{lc}
\hline Type of examination & n/total (\%) \\
\hline Positive direct examination & $36 / 38(94.7)$ \\
Capsular antigen detection & $14 / 14(100)$ \\
$\quad$ Serum reactive & $4 / 4(100)$ \\
CSF reactive & $10 / 10(100)$ \\
Positive culture & $34 / 38(89.5)$ \\
Serotype A & $32 / 34(94.1)$ \\
Serotype B & $2 / 34(5.9)$ \\
Molecular type & \\
VNI & $29(85.3)$ \\
VNII & $3(8.8)$ \\
VGII & $2(5.9)$ \\
Mating type & \\
a & $1(2.9)$ \\
alpha & $33(97.1)$ \\
Isolates recovered from & \\
CSF & $27(79.5)$ \\
CSF and blood & $3(8.9)$ \\
Blood & $1(2.9)$ \\
Skin & $1(2.9)$ \\
CSF, BAL and skin & $1(2.9)$ \\
Blood and BAL & $1(2.9)$ \\
\hline
\end{tabular}

BAL: bronchoalveolar lavage; CSF: cerebrospinal fluid. 
TABLE IV

Age, sex, prevalence and incidence of cryptococcosis in children in diverse countries around the world

\begin{tabular}{|c|c|c|}
\hline Region & $\begin{array}{l}\text { Age (years)/ } \\
\text { findings }(\%)\end{array}$ & Reference \\
\hline Colombia & 8.4 & This paper \\
\hline \multirow[t]{2}{*}{ Brazil } & $\begin{array}{l}7.6 \text { and } 7.8 \\
\text { (most HIV-) }\end{array}$ & Severo et al. (2009) \\
\hline & $\begin{array}{c}8.8 \\
\text { (all HIV-) }\end{array}$ & Corrêa et al. (2002) \\
\hline Cuba & $\begin{array}{c}5.8 \\
\text { (85.7 immunocompetent) }\end{array}$ & Illnait et al. (2013) \\
\hline \multirow[t]{2}{*}{ China } & $\begin{array}{c}7.25 \\
(\mathrm{HIV}-)\end{array}$ & Yuanjie et al. (2012) \\
\hline & $\begin{array}{c}10.9 \\
\text { (children up to } 17 \text { years) }\end{array}$ & Guo et al. (2012) \\
\hline South Africa & $\begin{array}{c}7 \\
(91 \mathrm{HIV}+)\end{array}$ & Meiring et al. (2012) \\
\hline Taiwan & $\begin{array}{c}13.7 \\
\text { (all HIV- up to } 17 \text { years) }\end{array}$ & Huang et al. (2010) \\
\hline Thailand & $\begin{array}{c}7 \\
\text { (all } \mathrm{HIV}+)\end{array}$ & Likasitwattanakul et al. (2004) \\
\hline \multirow[t]{4}{*}{ United States of America } & $\begin{array}{c}8 \\
\text { (all } \mathrm{HIV}+)\end{array}$ & Abadi et al. (1999) \\
\hline & $\begin{array}{c}9.8 \\
\text { (all HIV+) }\end{array}$ & Leggiadro et al. (1991) \\
\hline & $\begin{array}{c}11.5 \\
(\text { all } \mathrm{HIV}+)\end{array}$ & González et al. (1996) \\
\hline & $\begin{array}{c}11.98 \\
\text { (79.4 immunocompromised, } \\
\text { up to } 18 \text { years) }\end{array}$ & Joshi et al. (2010) \\
\hline Region & Sex male $(\%)$ & Reference \\
\hline Colombia & 58.5 & This paper \\
\hline Brazil & 52.8 & Severo et al. (2009) \\
\hline Northern Brazil & 54.5 & Corrêa et al. (1999) \\
\hline Cuba & 42.9 & Illnait et al. (2013) \\
\hline China & 60.87 & Guo et al. (2012) \\
\hline \multirow[t]{2}{*}{ South Africa } & 54.9 & Miglia et al. (2011) \\
\hline & 57 & Meiring et al. (2012) \\
\hline Taiwan & 22.2 & Huang et al. (2010) \\
\hline Thailand & 57.9 & Likasitwattanakul et al. (2004) \\
\hline United State of America & 60.3 & Joshi et al. (2010) \\
\hline Region & Prevalence (\%) & Reference \\
\hline Colombia & 2.6 & This paper \\
\hline Norte de Santander & 29.6 & Lizarazo et al. (2012) \\
\hline \multicolumn{3}{|c|}{ Northern/northeastern Brazil } \\
\hline State of Bahia & 32 & Darzé et al. (2000) \\
\hline State of Pará & 24 & Corrêa et al. (1999) \\
\hline State of Piauí & 9.5 & Martins et al. (2011) \\
\hline \multicolumn{3}{|l|}{ Africa } \\
\hline Botswana & 2.4 & Mullan et al. (2011) \\
\hline Ghana & 6.9 & Owusu et al. (2012) \\
\hline South Africa & 2 & Miglia et al. (2011) \\
\hline
\end{tabular}




\begin{tabular}{lcc}
\hline Region & Prevalence (\%) & Reference \\
\hline Thailand & 3 & Likasitwattanakul et al. (2004) \\
United States of America & 0.85 & González et al. (1996) \\
& 1.4 & Abadi et al. (1999) \\
French Guiana & 3.3 & Harris et al. (2012) \\
Uruguay & 4.6 & Debourgogne et al. (2011) \\
Venezuela & 1.3 & Quian et al. (2012) \\
\hline & 0.91 & Pérez et al. (2009) \\
Region & Incidence & \\
& (cases x 100,000) & Reference \\
Colombia & 0.016 & This paper \\
Norte de Santander & 0.113 & This paper \\
China & 0.43 & Guo et al. (2012) \\
South Africa & 1 & Meiring et al. (2012) \\
Gauteng & 47 (HIV+) & McCarthy et al. (2006) \\
United States of America & $38(\mathrm{HIV}+)$ & González et al. (1996) \\
\hline
\end{tabular}

terns VNI (85.3\%) and VNII $(8.8 \%)$ and $5.9 \%$ of the isolates belonged to serotype $\mathrm{B}$, molecular type VGII (Table III). From the nine cases identified in Norte de Santander, six isolates were studied and all of them were serotype A, molecular type VNI.

Literature review - The results of the review are listed in Table IV.

\section{DISCUSSION}

As has been reported in the literature, cryptococcosis is a rare disease in children worldwide, including in Colombia (Abadi et al. 1999, McCarthy et al. 2006, Meiring et al. 2012).

Age - The average age of infected children (8.4 years) found in this study is similar to that found in other studies: seven years in South Africa (91\% HIV+) (Meiring et al. 2012), seven years in Thailand (all HIV+) (Likasitwattanakul et al. 2004), 7.25 years in China (HIV-) (Yuanjie et al. 2012), 7.6, 7.8 and 8.8 years in Brazil (the majority HIV-) (Corrêa et al. 1999, 2002, Severo et al. 2009) and eight and 9.8 years in the United States of America (USA) (all HIV+) (Leggiadro et al. 1991, Abadi et al. 1999). The average age is greater in China, at 10.9 years (all HIV-) (Guo et al. 2012); in other studies from the USA, at 11.5 years (all HIV+) (González et al. 1996) and 11.98 years (79.4\% immunocompromised) (Joshi et al. 2010) and in Taiwan 13.7\% (all HIV-) (Huang et al. 2010). In an American study (Joshi et al. 2010), patients of up to 18 years old were included and in studies from China and Taiwan, patients up to 17 years old were included (Huang et al. 2010, Guo et al. 2012), a fact that could slant the result and increase the average value. In a small Cuban study, the average of age was younger, 5.8 years (85.7\% immunocompetent) (Illnait et al. 2013). In our study, two children less than one year old appeared, a finding only frequent in South Africa, where cryptococcosis in children has a bimodal presentation with a peak at less than one year old and another that appears from five-10 years of age. The high incidence of cryptococcosis in children less than one year is explained in South Africa by the vertical transmission of HIV infection (Meiring et al. 2012).

Sex - In this study, there was a slight predominance of the male sex $(58.5 \%)$ and similar results were observed in studies from Brazil, 52.6\% (Corrêa et al. 1999) and $52.8 \%$ (Severo et al. 2009), South Africa, 54.9\% (Miglia et al. 2011) and 57\% (Meiring et al. 2012), Thailand, $57.9 \%$ (Likasitwattanakul et al. 2004), China, $60.87 \%$ (Guo et al. 2012) and the USA, 60.3\% (Joshi et al. 2010). Some small studies have reported a predominance of the female sex in Taiwan, $77.8 \%$ (Huang et al. 2010), and Cuba, 57.1\% (Illnait et al. 2013). The predominance of the male sex is more evident in adults, especially in the population infected by HIV (Dromer et al. 1996).

Risk factor - Almost half (46.3\%) of the studied patients did not have a known risk factor, a quarter (24.4\%) had HIV infection and the rest had other conditions that depressed cellular immunity. In the global literature, studies have been described where all or almost all of the patients had AIDS (Leggiadro et al. 1991, Abadi et al. 1999, Gumbo et al. 2002, Likasitwattanakul et al. 2004, Meiring et al. 2012). Additionally, studies exist describing patients without AIDS, but with a percentage of underlying disease, e.g., Guo et al. (2012) (26.1\%) and Huang et al. (2010) (56\%), as do studies of only immunocompetent patients (Yuanjie et al. 2012). Other studies exist that include patients with all these possibilities, such as ours and that of Joshi et al. (2010), with 20.6\% immunocompetent patients, $22.2 \%$ displaying malignancy, $15.9 \% \mathrm{HIV}+$ and $41.3 \%$ displaying other co-morbidities and that of Severo et al. (2009), with $24.1 \%$ HIV, $25.9 \%$ immunocompetent (half of these infected with $C$. gattii) and 50\% with another co-morbidity. It is important to highlight the high 
percentage of immunocompetent patients in our series, which is similar to that described in China, Taiwan and Brazil (dos Santos et al. 2008, Huang et al. 2010, Martins et al. 2011, Freire et al. 2012, Guo et al. 2012).

Prevalence - In South Africa, it was estimated that between $0.9-2 \%$ of cryptococcosis occurs in children younger than 15 years (McCarthy et al. 2006, Meiring et al. 2012). Additionally, in this same country, $2 \%$ of clinical isolates of Cryptococcus sp. come from children and 96\% of these are HIV+ (Miglia et al. 2011). In Ghana, cryptococcosis is responsible for $6.9 \%$ of meningitis cases, with positive cultures in children under 18 years (Owusu et al. 2012), and in Botswana, 2.36\% of the meningeal cryptococcosis with positive cultures occur in children $<13$ years (Mullan et al. 2011).

In the northern and northeastern regions of Brazil, a series of childhood cryptococcosis cases have been reported with a high prevalence rate: $32 \%$ in the state of Bahia (Darzé et al. 2000), 24\% in the state of Pará (Corrêa et al. 1999) and $9.5 \%$ in the state of Piauí (Martins et al. 2011). In contrast, French Guiana reported a prevalence of $4.6 \%$ (Debourgogne et al. 2011). In the USA, the prevalence is lower $(0.85-1.4 \%)$ in HIV-infected children (González et al. 1996, Abadi et al. 1999), as is the number of hospitalisations for cryptococcosis, which reached a rate of 6.2 million (Joshi et al. 2010). In Thailand, $2.97 \%$ of hospitalised HIV+ children under 16 years had cryptococcosis (Likasitwattanakul et al. 2004) and among those younger than 19 years of age hospitalised for pneumonia, 3.3\% have positive serum antigen for Cryptococcus, all of them HIV+ (Harris et al. 2012). In Latin America, Uruguay registers a prevalence of $1.3 \%$ of cryptococcosis in HIV+ children (Quian et al. 2012) and Venezuela reported a prevalence of $0.91 \%$ in the general population (Pérez et al. 2009). The prevalence of $2.6 \%$ in Colombian children is equally low; however, in a study of meningeal cryptococcosis in HIV- patients in Norte de Santander, 29.6\% were children under the age of 16 years (Lizarazo et al. 2012), a fact similar to the one reported in northern Brazil (Corrêa et al. 1999, Darzé et al. 2000). Significantly, northern Brazil and Norte de Santander are characterised by a high prevalence of $C$. gattii infection in immunocompetent patients (Corrêa et al. 1999, Lizarazo et al. 2012).

Incidence - Additionally, there are few data on the incidence of cryptococcosis in children. In South Africa, it was calculated that for the year 2007, there was an incidence of one case per 100,000 children in the general population and 47 cases per 100,000 HIV+ children (Meiring et al. 2012).

In that same country, in the Gauteng province, which has a high rate of prevalence of HIV infection, the incidence of disease is estimated at 38 cases per 100,000 $\mathrm{HIV}+$ children (McCarthy et al. 2006). In an USA study from the end of the last century, an annual incidence of $0.1 \%$ among the paediatric population of HIV+ individuals was reported (González et al. 1996). Recently, China reported an incidence of 0.43 cases per 100,000 children less than 18 years (Guo et al. 2012). The incidence of 0.016 cases per 100,000 children under the age of 16 years reported for Colombia in this study is very low compared with what has been reported in other countries; however, in Norte de Santander, the mean annual incidence is seven times higher (0.122 per 100,000), a significant difference from the rest of the country $(p<0.0001)$.

The reason for the low presentation of cryptococcosis in children has not been established. It is thought that it is not because of a lack of exposure because a study revealed the presence of $\operatorname{IgG}$ and $\operatorname{IgM}$ antibodies against the capsule glucuronoxylomannan of Cryptococcus sp., both in HIV+ and HIV-children, a fact that supports the idea of an exposure to the fungus or the presence of a subclinical infection early in childhood (Abadi \& Pirofski 1999). Another study carried out in the Bronx, New York, showed that the vast majority of children had antibodies against Cryptococcus sp. at the age of two years and that this response persisted throughout childhood (Goldman et al. 2001).

The clinical presentation of disease was mainly neurocryptococcosis $(87.8 \%)$, a fact also recognised by the majority of the case series (Leggiadro et al. 1991, Abadi et al. 1999, Corrêa et al. 1999, Gumbo et al. 2002, Likasitwattanakul et al. 2004, Severo et al. 2009, Huang et al. 2010, Guo et al. 2012, Meiring et al. 2012, Yuanjie et al. 2012), with the exception of the study of Joshi et al. (2010) where the extraneural cryptococcosis was more frequently observed than meningeal cryptococcosis $(62 \%$ vs. $38 \%)$. The most frequent clinical manifestations of headache, fever, nausea and vomiting, mental confusion and meningeal signs are common in most of the published cases. It should be noted that, as in adults, the meningeal signs have a low positivity $(37.5 \%)$ (Lizarazo et al. 2007, Escandón et al. 2012). Unfortunately, the value of the opening pressure of the CSF is not specified and, therefore, we could not establish the percentage of children with intracranial hypertension without hydrocephalus, which in adults exceeds 50\% (Lizarazo et al. 2012). In only two paediatric series, the value of the CSF pressure was determined and, in both, the percentage of patients with intracranial hypertension was very high: $73.9 \%$ in Guo et al. (2012) and 83\% in Likasitwattanakul et al. (2004). Almost a fifth of the patients had hydrocephalus, a serious complication of meningeal cryptococcosis. Respiratory compromises were rare and only observed in two patients $(4.9 \%)$ where the fungus was able to be recovered from bronchoalveolar lavage; likewise, in very few patients $(12.2 \%)$ were the results of the chest X-ray reported. However, the majority of these patients displayed abnormalities. In only a third of patients, the results of a skull CT were reported, which were abnormal in two-thirds; the abnormalities were multiple, but non-specific. Corrêa et al. (2002) reported a series of immunocompetent children with meningitis caused by $C$. gattii with the presence of hypodense nodules in all of them. To a lesser degree, diffuse cerebral atrophy and hydrocephalus was observed; these last two abnormalities coexisted in some cases. In this series, we do not report results of MRI studies.

Treatment was mostly with AmB, alone or in multiple combinations. The treatment of choice for the meningeal cryptococcosis, which was the prevailing form of presentation in our series, is the association of $\mathrm{AmB}+$ 5-fluorocytosin. Although there are no controlled stud- 
ies in children, the results of studies in adults have been extrapolated to children and their use has been recommended by international guidelines for management of this disease (Perfect et al. 2010).

The mycological diagnosis was made in the vast majority of the cases in the CSF through direct visualisation of the encapsulated yeast cells in the CSF (sensitivity of $94.7 \%$ ) and for CSF, blood, bronchoalveolar lavage or skin cultures (sensitivity $85.4 \%$ ). On a smaller scale, the detection of the Cryptococcus capsular antigen in $\mathrm{CSF}$ and serum was used. These findings are similar to those reported by other investigators (Abadi et al. 1999, Corrêa et al. 1999, Likasitwattanakul et al. 2004, Severo et al. 2009, Huang et al. 2010, Guo et al. 2012, Meiring et al. 2012) and highlight the utility of direct studies and of culture in the diagnosis of cryptococcosis.

A few of the published reports determined the type of species responsible for cryptococcosis (Severo et al. 2009, Meiring et al. 2012). C. neoformans var. grubii is responsible for the majority of cryptococcosis in the world and, to a greater extent, in patients who are HIV+ (Antinori 2013). The percentage of 5.9\% C. gattii in Colombian children is high if compared with the findings of cryptococcosis in the general population of Colombia (3.4-3.8\%) (Lizarazo et al. 2007, Escandón et al. 2012). In South Africa, $7 \%$ of paediatric infections are caused by $C$. gattii (Meiring et al. 2012) while in Brazil the percentage is much higher, $29.6 \%$ (Severo et al. 2009).

In recent years, interest in cryptococcosis in children has been on the rise. The National Survey on Cryptococcosis that is being conducted passively in our country has allowed us to estimate the prevalence of cryptococcosis in children in Colombia. However, epidemiological data are still scarce, the factors that determine its relative rarity in the childhood population are still poorly understood and there are no own management guides. Undoubtedly, new studies are needed to improve the handling of children affected by this fungal infection.

\section{ACKNOWLEDGEMENTS}

To the Colombian group for the study of cryptococcosis, for submitting the surveys, and to the reviewers, for their comments.

\section{REFERENCES}

Abadi J, Nachman S, Kressel AB, Pirofski L 1999. Cryptococcosis in children with AIDS. Clin Infect Dis 28: 309-313.

Abadi J, Pirofski L 1999. Antibodies reactive with the cryptococcal capsular polysaccharide glucuronoxylomannan are present in sera from children with and without human immunodeficiency virus infection. J Infect Dis 180: 915-919.

Antinori S 2013. New insights into HIV/AIDS-associated cryptococcosis. ISRN AIDS 2013: 471363.

Corrêa MP, Oliveira EC, Duarte RR, Pardal PP, Oliveira FM, Severo LC 1999. Criptococose em crianças no estado do Pará, Brasil. Rev Soc Bras Med Trop 32: 505-508.

Corrêa MP, Severo LC, Oliveira FM, Irion K, Londero AT 2002. The spectrum of computerized tomography (CT) findings in central nervous system (CNS) infection due to Cryptococcus neoformans var. gattii in immunocompetent children. Rev Inst Med Trop Sao Paulo 44: 283-287.
DANE - Departamento Nacional de Estadísticas 2013. Proyecciones de población. Available from: dane.gov.co/index.php/poblaciony-demografia/proyecciones-de-poblacion.

Darzé C, Lucena R, Gomes I, Melo A 2000. Características clínicas laboratoriais de 104 casos de meningoencefalite criptocócica. Rev Soc Bras Med Trop 33: 21-26.

Dean AG, Dean JA, Columbier D, Burton AH, Brendel KA, Smith DC, Dicker RC, Sullivan KM, Fagan RF 1994. Epi Info version 6.0: a wordprocessing, data-base and statistics program for epidemiology on microcomputers, Centers for Disease Control and Prevention, Atlanta, 603 pp.

Debourgogne A, Iriart X, Blanchet D, Veron V, Boukhari R, Nacher M, Carme B, Aznar C 2011. Characteristics and specificities of Cryptococcus infections in French Guiana, 1998-2008. Med Mycol 49: 864-871.

dos Santos WRA, Meyer W, Wanke B, Costa SPSE, Trilles L, Nascimento JLM, Medeiros R, Morales BP, Bezerra CCF, de Macêdo RCL, Ferreira SO, Barbosa GG, Perez MA, Nishikawa MM, Lazéra MS 2008. Primary endemic cryptococcosis gattii by molecular type VGII in the state of Pará, Brazil. Mem Inst Oswaldo Cruz 103: $813-818$.

Dromer F, Mathoulin S, Dupont B, Laporte A 1996. Epidemiology of cryptococcosis in France: a 9-year survey (1985-1993). French Cryptococcosis Study Group. Clin Infect Dis 23: 82-90.

Escandón P, de Bedout C, Lizarazo J, Agudelo CI, Tobón A, Bello S, Restrepo A, Castañeda E, Grupo Colombiano para el Estudio de la Criptococosis 2012. Cryptococcosis in Colombia: results of the national surveillance program for the years 2006-2010. Biomedica 32: 386-398.

Freire AK, Bentes AS, Sampaio IL, Matsuura AB, Ogusku MM, Salem JI, Wanke B, de Souza JV 2012. Molecular characterization of the causative agents of cryptococcosis in patients of a tertiary healthcare facility in the state of Amazonas-Brazil. Mycoses 55: e145-e150.

Goldman DL, Khine H, Abadi J, Lindenberg DJ, Pirofski LA, Niang R, Casadevall A 2001. Serologic evidence for Cryptococcus neoformans infection in early childhood. Pediatrics 107: e66.

González CE, Shetty D, Lewis LL, Mueller BU, Pizzo PA, Walsh TJ 1996. Cryptococcosis in human immunodeficiency virus-infected children. Pediatr Infect Dis J 15: 796-800.

Gumbo T, Kadzirange G, Mielke J, Gangaidzo IT, Hakim JG 2002. Cryptococcus neoformans meningoencephalitis in African children with acquired immunodeficiency syndrome. Pediatr Infect Dis J 21: 54-56.

Guo J, Zhou J, Zhang S, Zhang X, Li J, Sun Y, Qi S 2012. A case-control study of risk factors for HIV-negative children with cryptococcal meningitis in Shi Jiazhuang, China. BMC Infect Dis 12: 376.

Halliday CL, Carter DA 2003. Clonal reproduction and limited dispersal in an environmental population of Cryptococcus neoformans var. gattii isolates from Australia. J Clin Microbiol 41: 703-711.

Harris JR, Lindsley MD, Henchaichon S, Poonwan N, Naorat S, Prapasiri P, Chantra S, Ruamcharoen F, Chang LS, Chittaganpitch M, Mehta N, Peruski L, Maloney SA, Park BJ, Baggett HC 2012. High prevalence of cryptococcal infection among HIV-infected patients hospitalized with pneumonia in Thailand. Clin Infect Dis 54: e43-e 50.

Huang KY, Huang YC, Hung IJ, Lin TY 2010. Cryptococcosis in non-human immunodeficiency virus-infected children. Pediatr Neurol 42: 267-270.

Illnait MT, Martínez GF, Fernández CM, Marchena JJ, Perurena MR 2013. Contribución al estudio de la criptococosis infantil en Cuba. Rev Cubana Med Trop 65: 78-89. 
Joshi NS, Fisher BT, Prasad PA, Zaoutis TE 2010. Epidemiology of cryptococcal infection in hospitalized children. Pediatr Infect Dis J 29: e91-e95.

Kwon-Chung KJ, Polacheck I, Bennett JE 1982. Improved diagnostic medium for separation of Cryptococcus neoformans var. neoformans (serotypes A and D) and Cryptococcus neoformans var. gattii (serotypes B and C). J Clin Microbiol 15: 535-537.

Leggiadro RJ, Kline MW, Hughes WT 1991. Extrapulmonary cryptococcosis in children with acquired immunodeficiency syndrome. Pediatr Infect Dis J 10: 658-662.

Likasitwattanakul S, Poneprasert SB, Sirisanthana V 2004. Cryptococcosis in HIV-infected children. Southeast Asian J Trop Med Public Health 35: 935-939.

Lizarazo J, Chaves O, Peña Y, Escandón P, Agudelo CI, Castañeda E 2012. Comparación de los hallazgos clínicos y de supervivencia entre pacientes VIH positivos y VIH negativos con criptococosis meníngea en un hospital del tercer nivel. Acta Med Colomb 37: 49-61.

Lizarazo J, Linares M, de Bedout C, Restrepo A, Agudelo CI, Castañeda E, Grupo Colombiano para el Estudio de la Criptococosis 2007. Estudio clínico y epidemiológico de la criptococosis en Colombia: resultados de nueve años de la encuesta nacional, 19972005. Biomedica 27: 94-109.

Martins LMS, Wanke B, Lazéra MS, Trilles L, Barbosa GG, de Macedo RCL, Cavalcanti MAS, Eulálio KD, de Castro JAF, da Silva AS, do Nascimento FF, Gouveia VA, do Monte SJH 2011. Genotypes of Cryptococcus neoformans and Cryptococcus gattii as agents of endemic cryptococcosis in Teresina, Piauí (northeastern Brazil). Mem Inst Oswaldo Cruz 106: 725-730.

McCarthy KM, Morgan J, Wannemuehler KA, Mirza SA, Gould SM, Mhlongo N, Moeng P, Maloba BR, Crewe-Brown HH, Brandt ME, Hajjeh RA 2006. Population-based surveillance for cryptococcosis in an antiretroviral-naïve South African province with a high HIV seroprevalence. AIDS 20: 2199-2206.

Meiring ST, Quan VC, Cohen C, Dawood H, Karstaedt AS, McCarthy KM, Whitelaw AC, Govender NP, Group for Enteric, Respiratory and Meningeal Disease Surveillance in South Africa (GERMSSA) 2012. A comparison of cases of paediatric-onset and adultonset cryptococcosis detected through population-based surveillance, 2005-2007. AIDS 26: 2307-2314.

Meyer W, Castañeda A, Jackson S, Huynh M, Castañeda E, Ibero American Cryptococcal Study Group 2003. Molecular typing of
Ibero American Cryptococcus neoformans isolates. Emerg Infect Dis 9: 189-195.

Miglia KJ, Govender NP, Rossouw J, Meiring S, Mitchell TG, Group for Enteric, Respiratory and Meningeal Disease Surveillance in South Africa 2011. Analyses of pediatric isolates of Cryptococcus neoformans from South Africa. J Clin Microbiol 49: 307-314.

Mullan PC, Steenhoff AP, Draper H, Wedin T, Bafana M, Anabwani G, Jibril H, Tshepo M, Schutze GE 2011. Etiology of meningitis among patients admitted to a tertiary referral hospital in Botswana. Pediatr Infect Dis J 30: 620-622.

Owusu M, Nguah SB, Boaitey YA, Badu-Boateng E, Abubakr AR, Lartey RA, Adu-Sarkodie Y 2012. Aetiological agents of cerebrospinal meningitis: a retrospective study from a teaching hospital in Ghana. Ann Clin Microbiol Antimicrob 11: 28.

Park BJ, Wannemuehler KA, Marston BJ, Govender N, Pappas PG, Chiller TM 2009. Estimation of the current global burden of cryptococcal meningitis among persons living with HIV/AIDS. AIDS 23: 525-530.

Pérez C, Hernández Y, Guzmán ME, Arias F, Nweilhed L, Landaeta ME, Borges R, Madera C, Roselló A, Colella MT, Hartung C, Mata S 2009. Estudio clínico-epidemiológico de la criptococosis en Venezuela, años 1994-2003. Kasmera 37: 140-147.

Perfect JR, Dismukes WE, Dromer F, Goldman DL, Graybill JR, Hamill RJ, Harrison TS, Larsen RA, Lortholary O, Nguyen MH, Pappas PG, Powderly WG, Singh N, Sobel JD, Sorrell TC 2010. Clinical practice guidelines for the management of cryptococcal disease: 2010 update by the Infectious Diseases Society of America. Clin Infect Dis 50: 291-322.

Quian J, Gutiérrez S, González V, Sánchez M, Abayian M, Baccino F 2012. Meningitis por Cryptococcus neoformans en niños y adolescentes infectados por virus de la inmunodeficiencia humana. Rev Chilena Infectol 29: 554-557.

Severo CB, Xavier MO, Gazzoni AF, Severo LC 2009. Cryptococcosis in children. Paediatr Respir Rev 10: 166-171.

Viviani MA 1997. Epidemiological working groups of ECMM. Mycology Newsletter 2: 4-5.

Yuanjie Z, Jianghan C, Nan X, Xiaojun W, Hai W, Wanqing L, Julin G 2012. Cryptococcal meningitis in immunocompetent children. Mycoses 55: 168-171. 